\title{
Short term versus conventional Catheterisation after Genital Prolapse Surgery
}

\author{
KHURSHIDA TAHMIN ${ }^{1}$, SHAMSUN NAHAR BEGUM(HENA) ${ }^{2}$
}

\begin{abstract}
:
This Randomised controlled clinical trial was undertaken to determine the suitable time of catheter removal after urogenital prolapse surgery in order to reduce the catheter related UTI and its long term sequel.

Method: Total 80 patients undergoing vaginal hysterectomy with pelvic floor repair were enrolled and randomised into two equal groups by lottery method. Trans-urethral catheter was removed on 2 nd \& 5th post operative day in group I $(n=40)$ and in group II $(n=40)$ respectively. Post voidal residual urine volume before operation and after removal of catheter was measured in all patients by ultrasound scanning. Re-catheterisation was done for three more days if residual volume $>200 \mathrm{ml}$ after removal of catheter. Urine samples were taken before removal of catheter and send for routine microscopic examination and culture \& sensitivity test to detect UTI.

Results: Removal of catheter on $2^{\text {nd }}$ post-operative day lead to significant reduction of rate of UTI. The rate of UTI following removal of catheter was $7.5 \%$ versus $42.5 \%$ in group I and in group II $(p<0.001)$. But need for recatheterisation was significantly higher in group I (15\%) than in group II (2.5\%). The mean duration of catheterisation was $47.63( \pm 0.628)$ and 119.35 $( \pm 0.864)$ hours in group I and group II respectively. Majority of the patients in group I did not require prolongation of catheterisation. Mean duration of hospital stay after operation was 5 days in group I and 7.95 days in group II $(p<0.001)$.

Conclusion: Short period catheterisation is associated with lower rate of UTI and shorter hospital stay. Disadvantages of prolonged catheterisation outweigh the advantages. Therefore removal of the catheter on the $2^{\text {nd }}$ post-operative day after genital prolapse surgery is preferable than 5 days catheterisation.
\end{abstract}

Key words: Vaginal hysterectomy, catheterisation, catheter related UTI, re-catheterisation, hospital stay.

\section{Introduction:}

After vaginal operations for prolapse the use of indwelling catheter is usual as the patient is unable to pass urine on her own accord. There is chance of retention of urine due to post operative tissue swelling, pain, transient bladder atony, haematoma, haemostatic vagina pack. Catheterisation for five days after vaginal prolapse surgery is an accepted practice. Postoperative urinary retention is associated with risk of overdistention and permanent detrusor damage.$^{1}$ As a result complete emptying of the urinary bladder becomes impossible and increased infection rate may result .2

But prevention of urinary retention by insertion of indwelling catheter also increases the risk of urinary tract infection. The risk of catheter related UTI increases with length of time a catheter is in situ. ${ }^{3}$ The available information from urologic reports and institutionalised patients demonstrates a $3 \%$ to $10 \%$ increased risk of bacteriuria per day of catheterisation..$^{3,4}$ The best way to prevent catheter related UTI is removal of catheter as soon as possible.

Long time catheterisation also delays ambulation, prolongs hospital stay and increases hospital cost. In prolapse surgery there is not so much interference in nerve supply of bladder and urethra, so short term catheterisation after surgery is tried now a days. ${ }^{2}$

The question of how long catheter should remain in situ after surgery has been debated for several years and has not yet been resolved. In our routine practice,

1. Junior consultant (Current charge), Upazilla Health Complex, Jaganathpur, Sunamganj.

2. Prof. \& Head, Dept. Of Obst \&Gynae, Sylhet M.A.G. Osmani Medical College Hospital 
the actual proportion of patients requiring prolonged catheterisation remains unknown.

Although there is no consensus regarding the best time for catheter removal, recent trend is in favour of earlier removal. Many studies have shown that early catheter removal (after 24 hour) is beneficial. Only disadvantage is higher rates of recatheterisation because of urinary retention. The high recatheterisation rates associated with early catheter removal introduce uncertainty about the benefits of early removal. But higher rate of UTI associated with prolonged catheterisation concludes that catheterisation for 5 days after surgery is too long. As removal of catheter after 24 hours increase the rate of recatheterisation, which may cause lower urinary tract infection.

So this study has been designed to find out the advantage of early removal (2nd POD)) over late removal (5th POD) following vaginal hysterectomy.

\section{Methodology:}

This randomised controlled clinical trial was conducted from July 2007 to June 2008 on patient of urogenital prolapse surgery as thesis topic in Department of Obstetrics and Gynaecology, Sylhet M.A.G. Osmani Medical College Hospital. Informed consent was obtained from each woman, and protocol was approved by ethical committee. After proper evaluation genital prolapse cases awaiting for vaginal hysterectomy and or pelvic floor repair, were enrolled for the study. Urine routine microscopic examination and culture \& sensitivity test were done to exclude pre existing UTI. Blood for random blood sugar was done to exclude diabetes mellitus.

Total 80 patients were enrolled and randomised into two groups, study group (group I, n-40) and control group (group II, n-40) by lottery method. To facilitate that process equal numbers of pre-labelled pieces of papers ( 40 for short period and 40 for conventional period of catheterisation) were placed and mixed thoroughly in a box.

To determine whether participants will be in group I or in group II, one piece of paper was picked up from the box at a time. These steps were repeated until desired number of patients has been recruited. The variables were assessed for each group are mean duration of catheterisation, rate of re-catheterisation, UTI \& hospital stay.

Trans-urethral catheter was removed on $2^{\text {nd }}$ and $5^{\text {th }}$ post operative day in group I \& group II respectively. Post void residual urine volume (PVR) before operation and after removal of catheter was measured in all patients by ultrasound scanning. Re-catheterisation was done for further three days when residual volume was more than $200 \mathrm{ml}$ following $6 \mathrm{hr}$ of catheter removal. Urine samples were taken before removal of catheter for routine microscopic examination and culture sensitivity test. UTI was defined as the presence of $>10^{5}$ colony forming units $/ \mathrm{ml}$ in the culture.

Data was collected by pre designed data collection sheet devised for the study. Quantitative data was analysed by mean and SD and qualitative data was summarised by percentage. Significance test was done by Student's ' $t$ ' test or Chi-square $\left(\mathrm{x}^{2}\right)$ test. $\mathrm{P}<$ .05 was considered as significant and $\mathrm{P}<.01$ was considered as highly significant.

\section{Results:}

Total 80 patients undergoing vaginal hysterectomy with pelvic floor repair were enrolled and randomised into two equal groups by lottery method. Trans-urethral catheter was removed on 2 nd \& 5 th post operative day in group I $(n=40)$ and in group II $(n=40)$ respectively. Post voidal residual urine volume before operation and after removal of catheter was measured in all patients by ultrasound scanning.

Table-I

Baseline characteristics of study population.

\begin{tabular}{lccc}
\hline Baseline characteristics & $\begin{array}{c}\text { Short period } \\
\text { catheterisation } \\
\text { group I }(\mathrm{n}-40)\end{array}$ & $\begin{array}{c}\text { Conventional period } \\
\text { catheterisation } \\
\text { group II }(\mathrm{n}-40)\end{array}$ & Significance \\
\hline Age & $51.75( \pm 10.8)$ & $53.95( \pm 12.8)$ & $p>0.05$ \\
Interventions- & 37 & 36 & $p>0.05$ \\
Vag.hysterectomy \& pelvic floor repair- & 3 & 4 & \\
Vag.hysterectomy and Anterior Colporrhaphy & $57.25( \pm 11.1)$ & $55.75( \pm 9.7)$ & $p>0.05$ \\
Operating time (minutes) & &
\end{tabular}

*Values within parenthesis are standard deviation. 
Table-II

Outcome variable.

\begin{tabular}{lccc}
\hline Variables & $\begin{array}{c}\text { Short period } \\
\text { catheterisation } \\
\text { Gr-I }(\mathrm{n}-40)\end{array}$ & $\begin{array}{c}\text { Conventional } \\
\text { catheterisation } \\
\text { Gr II }(\mathrm{n}-40)\end{array}$ & Significance \\
\hline Mean duration of catheterisation (hrs) & 47.63 & 119.35 & $p<0.001$ \\
Re-catheterisation $(n)$ & $6(15)$ & $1(2.5)$ & $p<0.001$ \\
Urinary tract infections $(n)$ & $3(7.5)$ & $17(42.5)$ & OR- 4.7862 \\
Mean hospital stay (days) & 5 & 7.95 & $p<0.001$ \\
\hline
\end{tabular}

*Values in parentheses are in \%.

Table I. showing no significant difference between the two groups in respect of age, type of operation and mean operating time.

Table II showed a significant number of patients (n-6) requiring re-catheterisation in group I compared with those in group II $(p<0.001)$.

The rate of UTI was significantly higher in conventional period of catheterisation group $(p<0.001)$. Mean duration of hospital stay after operation was 5 days in group I and 7.95 days in group II.

\section{Discussion:}

The objective of this study was to evaluate the advantages of short period catheterisation in comparison to conventional catheterisation after urogenital prolapse surgery.

In this study mean duration of catheterisation was $47.63( \pm 0.628)$ and $119.35( \pm 0.864)$ hours in group I and group II respectively $(p<0.001)$.

The rate of UTI was $7.5 \%$ in group I and $42.5 \%$ in group II ( $p<0.001)$. So early removal of catheter reduces the rate of urinary tract infections.

These findings has similarity with a study where early removal of catheter on the morning after surgery led to a ten fold reduction of urinary tract infections. ${ }^{5}$

In another prospective study on 100 vaginal surgeries showed positive urine cultures in $4 \%$ and $22 \%$ cases in 1 day \& 3 days catheter group respectively $(p<0.001){ }^{6}$ There is $3-10 \%$ increased risk of urinary tract infection for each day of catheterisation. ${ }^{3}$

Another study showed positive urine culture in $6 \%$ and $16 \%$ in the short and long term catheterisation group respectively which corroborate with this index study. ${ }^{8}$
In a study, 40\% patients required re-catheterisation when catheter was removed on the morning after surgery ${ }^{5}$ while in present study $15 \%$ required recatheterisation. As catheter was removed on the $2^{\text {nd }}$ post operative day, so less number of recatheterisation was required compared to the above study.

Another study showed similar post operative voiding problems in one and three days of catheterisation, ${ }^{8}$ which dose not corroborate with this study.

Another study on 257 vaginal hysterectomy with pelvic floor repair showed only 5 patients required recatheterisation for urinary retention. ${ }^{1}$

Despite the higher number of recatheterisation in short term catheter group, the mean duration of catheterisation was significantly shorter and the majority of patents (85\%) did not require prolongation of catheterisation.

There was significant difference $(P<0.001)$ in duration of post-operative hospital stay ( 5 days in group I and 7.95 days in group II) in between the two groups which was comparable to other study. ${ }^{10}$

Early catheter removal also significantly reduced the duration of post operative hospital stay as well as reduced the hospital cost

\section{Conclusions:}

This study showed that disadvantages of prolonged catheterisation outweigh the advantages. Short period catheterisation is associated with lower rate of UTI and shorter hospital stay. Therefore removal of the catheter on the $2^{\text {nd }}$ post-operative day after genital prolapse surgery is preferable and longer period catheterisation may be undertaken for specific indications.

Further large scale stydy is necessary to support the practice of short term catheterisation after genital 
prolapse surgery. Research work is also necessary to identify the factors that increase the risk of recatheterisation.

\section{References:}

1. Pant P.R. An effective short duration postoperative catheterisation after vaginal hysterectomy and pelvic floor repair. Journal of Institute of Medicin 2006; 28(1):33-35

2. Rosseland, L.A. Stubhaug, A. Breivik, H. Detecting postoperative urinary retention with an ultrasound scanner. Acta Anaesthesia Scand 2002;46(3):279-282.

3. Warren, J.W. Catheter associated urinary tract infections. Infect dis clin North Am 1997; 11(3):609-22.

4. Cardosi, R.J. Cardosi, R.P. Grendys, E.C. Fiorica, J.V. Hoffman, M.S. Infectious urinary tract morbidity with prolonged bladder catheterisation after radical hysterectomy. Am J Obstet Gynecol 2003;189:380-4.

5. Hakvoort, R.A. Elberink, R. Vollebregt, A. Van der Ploeg, T. Emanual, M.H. How long should urinary bladder catheterisation be continued after vaginal prolapse surgery? A randomised controlled trial comparing short term versus long term catheterisation after vaginal prolapse surgery. BJOG 2004;111:828-830.

6. Thakur, N. Gurung, G. Rana, A. A randomised controlled trial comparing short term versus long term catheterisation after vaginal prolapse surgery. NJ Obstet Gynaecol 2007; 2:29-34.

7. Verhout, M.E. Prolonged catheterisation after vaginal prolapse surgery. Acta Obstet Gynecol Scand 1998;77:997-999.

8. Chawdhury, F. R. 2007, 'Short term versus long term catheterisation after urogenital prolapse surgery', FCPS dissertation, BCPS.

9. Alonzo-Sosa, J.E. Flores-Contreras, J.T. Paredes-Canul, M. Method for transurethral catheterisation for 1-3 days for pelvic floor relaxation in the postoperative period. Ginecol Obstet (Mex) 1997; . 65:455-457.

10. Alessandri F,Mistrangelo E, Lijoi D.A prospective randomized trial comparing immediate versus delayed catheter removal following hysterectomy.Acta obstetrician et Gynecologica. 2006;85: 716-720. 